\title{
Políticas de formação para o trabalho e a socialização do conhecimento
}

\section{Education policies for work and the knowledge socialization}

Moacyr Salles Ramos*

Inez Stampa**

\begin{abstract}
Resumo - Este artigo se propõe a refletir sobre os limites e possibilidades da socialização do conhecimento científico e tecnológico no contexto das políticas contemporâneas de formação para o trabalho. Considera-se como elemento central do debate a questão da socialização do conhecimento como instrumentalização para a luta da classe trabalhadora contra o capital. Para tal, partimos das experiências de programas como o ProJovem, o Proeja e o Pronatec, aprofundando o debate sobre este último, apontando sua estratégia de submissão da classe trabalhadora, mediante a democratização da oferta de educação profissional sem socialização do conhecimento e elevação de escolaridade.
\end{abstract}

Palavras-chave: trabalho; políticas sociais; educação profissional; Pronatec.

\begin{abstract}
This article aims to reflect on the limits and possibilities of the socialization of scientific and technological knowledge in the context of contemporary policies for labor training. A central point to the debate is the question of the socialization of knowledge as instrumentalization for the struggle of the working class against capital. To do this, we start from experiences of programs such as Projovem, Proeja and Pronatec, debating the last one in depth, pointing out its strategy of working class submission through the democratic provision of education without socialization of knowledge and higher education. Keywords: labor; social policies; professional education; Pronatec.
\end{abstract}

\footnotetext{
* Doutorando em Serviço Social pela Pontifícia Universidade Católica do Rio de Janeiro (PUC-Rio). Atua como pedagogo na Faculdade de Educação da Universidade Federal Fluminense (UFF). Correspondência: Rua Professor Marcos Waldemar de Freitas s/no , Bloco D, sala 313, campus Gragoatá, São Domingos, Niterói/RJ. CEP: 24210-201. Email: <mramos@id.uff.br>.

${ }^{* *}$ Assistente social e socióloga (UERJ). Doutora em Serviço Social pela PUC-Rio. Professora adjunta do Departamento de Serviço Social e do Programa de Pós-Graduação em Serviço Social da PUC-Rio, do qual é atualmente coordenadora. Servidora do Arquivo Nacional/Ministério da Justiça, onde coordena o Centro de Referência das Lutas Políticas no Brasil (1964-1985) - Memórias Reveladas. Correspondência: Pontifícia Universidade Católica. Rua Marquês de São Vicente, 225 - Gávea, Rio de Janeiro/RJ. CEP: 22451-900 Email: <inestampa@ig.com.br>
} 


\section{Introdução}

Pensar as políticas sociais e o trabalho na sociedade capitalista é não só tentar compreender as várias contradições sociais existentes, mas também as formas de ler tais contradições. No caso do Brasil, entre outros fatores, implica pensar que, apesar de vivermos no país que tem o $7^{\circ}$ maior Produto Interno Bruto (PIB) do mundo, convivemos com um enorme atraso em nosso sistema educacional: cerca de 13 milhões de analfabetos com idade acima de 15 anos, alta taxa de distorção idade/série, entre outros dados alarmantes (IBGE, 2015). Então, por onde começar?

Dialogando com os escritos iniciais de Florestan Fernandes (19201995), percebemos sua luta para que o povo tivesse cultura e desenvolvesse a consciência crítica, universalizando, assim, a cidadania. Também fica claro que, durante muito tempo, o Estado brasileiro minou a criação de um sistema educacional público e democrático, fazendo com que seus recursos fossem destinados à expansão das escolas confessionais e particulares. Apesar de a ampliação da educação pública ser uma das bases para a democracia liberal, nossa burguesia, inicialmente, buscou impedir esse processo (FERNANDES, 1986; 1966).

Procurando entender esse cenário numa conjuntura política diferenciada, Florestan, em seus últimos escritos, conclui que, no sistema capitalista, a crescente flexibilidade tecnológica e econômica sempre corresponde a uma forte rigidez ideológica e política, abrindo o processo de negação da existência das classes sociais nas sociedades capitalistas ditas democráticas. Dizendo de outra forma, tratava-se da ideia de que a democracia no capitalismo pode substituir os ideais socialistas, a exemplo dos países centrais, que haviam "superado" os efeitos nocivos do capital (FERNANDES, 1975).

No entanto, essa superação não está ao alcance de todos os países. Isso porque, no arranjo societário do capitalismo, o mesmo se materializa como força social de formas distintas e específicas. Exemplo disso são os países da América Latina, cuja dependência é encarada como um atraso em relação ao avanço capitalista; contudo, de fato, esta é a forma como esse sistema se consolidou e permanecerá, pois a relação de dependência não pode ser superada progressivamente pela democracia, uma vez que não é apenas um estágio e sim uma condição. Nessa direção, o capitalismo dependente no Brasil é a realidade substantiva própria de nosso país no contexto capitalista. Nem o Estado nem a democracia liberal podem, portanto, exterminar essa relação de dependência e muito menos as relações de dominação no interior do nosso país. Porém, essa situação não coloca todos os brasileiros como vítimas, mas configura o processo de dominação conjugada entre a burguesia internacional e a nacional, especialmente sobre o trabalho (FERNANDES, 1975).

A condição de país de capitalismo dependente tem implicações diretas na estruturação de nosso sistema educacional e na forma homeopá- 
tica ou exclusivista como o conhecimento tem sido socializado. Diante disso, bastaria a luta pela democratização do sistema educacional dentro do capitalismo, se tal processo não resultasse necessariamente na total extinção da propriedade privada e da extração de mais-valia? Ou seja, permitir à classe trabalhadora o acesso à escola e a programas educacionais dará conta de transformar a relação de exploração capital versus trabalho? Como obter as ferramentas culturais necessárias ao enfrentamento da exploração capitalista sem acesso a um sistema educacional democrático e que forme sujeitos críticos?

Entendemos que a democratização da oferta de vagas seja importante, mas, se ela não articular formação para o trabalho com formação científica, cultural e filosófica, integrando teoria e prática, essa democratização tende a obnubilar a classe trabalhadora em sua organização e luta contra o capital. Desse modo, as especificidades da dominação burguesa no Brasil ainda nos apresentam grandes desafios, dentre os quais está a socialização do conhecimento no interior das instituições e programas educacionais. O resultado dependerá da correlação de forças entre as classes fundamentais na sociedade civil ${ }^{1}$, logo, na ossatura do Estado ampliado ${ }^{2}$. Além disso, nessa disputa, as classes não partem do mesmo lugar, nem possuem os mesmos conhecimentos e recursos.

Por essa razão, a proposta deste artigo é refletir sobre os limites e possibilidades dos programas de formação para o trabalho na elevação intelectual da classe trabalhadora e, consequentemente, em sua luta por emancipação. Tal questão é central no debate atual das políticas de formação para o trabalho em curso no Brasil, por isso apresentamos, brevemente, algumas notas sobre as principais transformações nessa área a partir dos anos 1990, contexto de criação de programas como o Programa Nacional de Inclusão de Jovens (ProJovem) e o Programa Nacional de Integração da Educação Profissional com a Educação Básica na modalidade de Educação de Jovens e Adultos (Proeja). Além disso, aprofundamos o debate com o Programa Nacional de Acesso ao Ensino Técnico e Emprego (Pronatec).

O foco dado ao Pronatec, neste artigo, não foi feito de modo aleatório, mas intencional. Isto porque este programa foi criado a fim de democratizar o acesso à educação profissional no Brasil, constituindo-se como o principal veículo no que tange às ações governamentais para a formação de trabalhadores desde a sua criação, no final de 2011. Sua centra-

\footnotetext{
${ }_{1}^{1}$ Partimos do referencial de Gramsci, para quem a sociedade civil é a arena em que as classes lutam para conquistar hegemonia, ou seja, direção política. É a esfera que resulta da socialização da política e faz parte do Estado, em sua essência (STAMPA, 2007). Para uma discussão mais aprofundada, ver, entre outros: Coutinho e Teixeira (2003); Semeraro (2001); Coutinho (1989) e Mello (1996).

${ }^{2}$ Consideramos os estudos de Gramsci, para quem o Estado ampliado é a soma da sociedade civil e da sociedade política. Ambas as esferas servem para conservar ou promover uma determinada base econômica de acordo com os interesses de uma classe social fundamental. Mas é na sociedade civil que as classes buscam aliados para as suas posições, ou seja, buscam exercer sua hegemonia.
} 
lidade tem atraído grande visibilidade social, como também gerado muitas expectativas para o enfrentamento das expressões da questão social ${ }^{3}$. Além disso, temos sobre esse programa dados empíricos, resultantes de uma pesquisa concluída no ano de $2014^{4}$, que nos ajudam a compreendê-lo para além dos documentos governamentais, ou seja, em sua materialização. Os resultados dessa pesquisa, somados à revisão bibliográfica aqui apresentada, buscam contribuir, sem a pretensão de finalizar ou de dar respostas definitivas, para a discussão em torno da educação destinada à classe trabalhadora no Brasil contemporâneo.

\section{A socialização do conhecimento no contexto da luta de classes}

No Brasil, a composição da classe burguesa tem preservado o seu caráter "organicamente senhorial e colonial", de modo que a constituição de um Estado de direito esteve historicamente travada como estratégia de dominação e policiamento da sociedade. Esse controle tem a sua gênese desde a relação com os escravos, passando pelos colonos, camponeses e proletários. Os pilares sustentadores dessa relação burguesa periférica foram, dentre outros, a coalisão entre as frações dominantes internas e externas na expansão do capital imperialista e a exacerbação da "defesa agressiva" do capitalismo nos países periféricos, nos quais a luta de classes é travada sem a flexibilidade necessária para a garantia de uma democracia burguesa (FERNANDES, 1984, p. 90-91).

Essa particularidade da nossa formação social tem relação direta com a constituição do direito à educação escolar, que no início do século XX já começa a se consolidar como condição para a participação social. Até a década de 1920, os movimentos populares que reivindicavam participação social também lutavam pelo acesso à escola como instrumento de participação política e democrática, num profundo "entusiasmo pela educação". No entanto, a partir de 1930, o viés político que conduzia o pensamento sobre a escola sofre uma inflexão, sendo superado pelo "otimismo pedagógico" do Movimento Escola Nova, que se fortalecia em países europeus e na América (SAVIANI, 2012b, p. 51).

A influência do Movimento Escola Nova, no Brasil, resultou no famoso Manifesto dos Pioneiros da Educação Nova, em 1932. Documento assinado por diversos intelectuais, postulava pela democratização da escola

${ }^{3}$ Com base em lamamoto (1998, p. 27), a questão social revela "o conjunto das expressões das contradições da sociedade capitalista madura, que tem uma raiz comum: a produção social é cada vez mais coletiva, o trabalho torna-se amplamente social, enquanto a apropriação dos seus frutos mantém-se privada, monopolizada por uma parte da sociedade". Para mais elementos sobre a questão social no Brasil, ver também: lanni (1989), Cerqueira Filho (1982) e Santos (2012).

${ }^{4}$ Este artigo apresenta alguns resultados da pesquisa finalizada no ano de 2014 no Programa de Pós-Graduação em Educação da Universidade Federal Rural do Rio de Janeiro (RAMOS, 2014). É também resultante de estudos desenvolvidos no âmbito do grupo de pesquisa Trabalho e Políticas Públicas do Programa de Pós-Graduação em Serviço Social da PUC-Rio. 


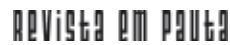

\} POLÍTICAS DE FORMAÇÃO PARA O TRABALHO - RAMOS, M. S.; STAMPA, I. \}

DOI: $10.12957 /$ REP.2016.27862

pública e gratuita a fim de responder às necessidades de modernização do país. Não obstante as virtudes desse movimento, cabe lembrar que é por meio dele que é dado total enfoque ao aspecto técnico-pedagógico, transferindo o foco dos conteúdos e dos objetivos para os métodos, esvaziando o debate político acerca da educação. Além disso, relativizou-se o ensino de acordo com as "condições de aprender de cada um", aprimorando, dessa forma, o ensino destinado às elites e rebaixando o nível do ensino destinado às camadas populares. Portanto, o referido movimento foi central para a recomposição da hegemonia ${ }^{5}$ burguesa, na medida em que foi apresentado pela burguesia, aparentemente, como espaço de fusão entre os interesses dessa classe e da classe trabalhadora, ou seja, de toda sociedade (SAVIANI, 2012b, p. 49-53).

Dessa forma, as lutas de frentes marxistas e anarquistas pela democratização de uma escola de acordo com os interesses da classe trabalhadora se dissolveram sob o prisma progressista que adquiriu o movimento escolanovista. Desse modo, ser progressista passou a significar ser escolanovista, uma espécie de unificação em torno dos interesses da nação. Não obstante a roupagem democrática, a escola se expande de modo extremamente precarizado, tanto no aspecto estrutural como pedagógico, estando distante dos ideais de uma pedagogia revolucionária, a qual:

[...] longe de secundarizar os conhecimentos descuidando de sua transmissão, considera a difusão de conteúdos, vivos e atualizados, uma das tarefas primordiais para o processo educativo em geral e da escola em particular [...] longe de entender a educação como determinante principal das transformações sociais, reconhece ser ela elemento secundário e determinado. Entretanto [...] entende que a educação se relaciona dialeticamente com a sociedade. (SAVIANI, 2012b, p. $65-66)$.

A organização da educação escolar está relacionada diretamente à divisão social do trabalho. Conforme apontado por Marx e Engels (2007) em A ideologia alemã, essa divisão obriga a separação entre trabalho industrial, comercial e agrícola, consequentemente, entre cidade e campo, além de subdivisões entre os indivíduos, determinando a relação entre eles no que tange à matéria, aos instrumentos e ao produto do trabalho. É também Marx (2012), em sua Crítica do programa de Gotha, que apresenta a impossibilidade de um tipo de escola para todos nos limites da sociedade capitalista, o que nos ajuda a compreender que a base econômica sempre buscará determinar os critérios para a socialização do conhecimento. Vejamos:

\footnotetext{
${ }^{5}$ Para Gramsci (1982), hegemonia é a direção política e ideológica de uma classe social sobre as outras. No contexto contemporâneo, tem sido da burguesia sobre a classe de trabalhadores. Conforme Dias (1999, p. 49), trata-se de um "projeto que permite expressar o programa, o horizonte ideológico, no qual as demais classes devem se mover. Horizonte que, ao proceder à padronização, ao conformismo, desorganiza, inviabiliza, ou tenta, os projetos das demais classes".
} 
Educação popular para todos? O que se quer dizer com essas palavras? Acredita-se, talvez, que na sociedade atual o ensino possa ser igual para todas as classes? Ou então, pretende-se que as classes superiores devam ficar coativamente limitadas àquele pouco de ensino - a escola popular - única compatível com as condições econômicas, tanto dos trabalhadores assalariados quanto dos camponeses? (MARX, 2012, p. 45).

As palavras de Marx permanecem atuais e nos ajudam a entender a constituição de escolas distintas para a burguesia, para a classe trabaIhadora e até para frações dessa classe, de acordo com interesses específicos do setor produtivo. Para a maior parcela da classe trabalhadora, além de uma escola básica precarizada, foi organizado um sistema de ensino que se dedicasse prioritariamente à formação profissional, ou seja, preparando os trabalhadores unicamente para o trabalho manual, sem a necessária articulação com a formação geral, com a socialização da cultura ${ }^{6}$ e com o acesso a níveis mais elevados de ensino ${ }^{7}$.

A partir de então, passa a ser ofertado apenas o saber necessário para o setor produtivo e para a conformação da classe trabalhadora, como se a ela estivessem sendo ofertadas as mesmas condições que as da classe dominante. Partindo da aplicação da ciência e da tecnologia no processo produtivo, mas sob a ótica do capital, essa educação profissional tem assumido um caráter fragmentador entre teoria e prática, trabalho manual e intelectual, impondo limites à classe trabalhadora pela socialização desigual do conhecimento e pelo subdesenvolvimento de suas capacidades intelectuais. Desse modo, o lugar social dos explorados acaba por interferir na construção do conhecimento, na dificuldade de desenvolver a dimensão ético-política necessária na disputa por hegemonia (SOUZA, 2002; DIAS, 1999).

A construção da hegemonia passa pela constituição de identidade, pela elevação intelectual, no sentido de ser capaz de construir um projeto ético-político revolucionário mesmo dentro da ordem capitalista. Para tal, é necessária "uma educação que exige a construção rigorosa de um saber mais avançado e socializado" (SEMERARO, 2006, p. 21).

É nesse sentido que a luta contra o capitalismo tem seu viés cultural e educativo, com foco na libertação da classe subordinada a fim de construir sua própria visão de mundo e preparar a base para uma revolução. Logo, o projeto de oposição ao capital deve empreender uma revolução intelectual pelo viés da cultura e da educação, cultivando o autoconhecimento, a autodisciplina, o estudo da história e o espírito crítico, pois os subalternos

\footnotetext{
${ }^{6}$ Entendemos cultura como concepção de mundo, como conjunto de significados que integram práticas sociais, não podendo ser entendida adequadamente sem a consideração das relações de poder embutidas nessas práticas, ou seja, no processo pelo qual o cultural se torna fato político. A esse respeito, ver Gramsci (1982).

${ }^{7}$ Situação fortemente agravada durante a Ditadura Militar, com a promulgação da Lei 5.692/71 (BRASIL, 1971), que além de permitir o aligeiramento da formação das camadas populares, instituiu a profissionalização como regra geral.
} 


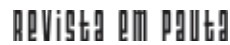

\} POLÍTICAS DE FORMAÇÃO PARA O TRABALHO - RAMOS, M. S.; STAMPA, I. \}

DOI: $10.12957 /$ REP.2016.27862

só poderão se libertar das minorias dominantes quando alcançarem um nível mais alto de conhecimento, tanto de si mesmos como da história dessa elite (GRAMSCI, 2001).

O movimento de luta deve ser direcionado para garantir a formação humanista e também prática, ou seja, uma escola que, apesar das limitações impostas pelo capital, esgarce as contradições através do desenvolvimento das capacidades intelectuais dos indivíduos e os prepare tanto para o trabalho manual como para se tornarem dirigentes (GRAMSCI, 2001, p. 33-34).

Na época de Gramsci havia uma forte tendência, ainda atual, de abolir ou conservar um pequeno número de escolas "desinteressadas" e "formativas" para a educação das elites, que não precisavam de preparo profissional, e havia, ainda, a difusão de escolas profissionais, ou seja, escolas do trabalho, para a classe subalterna. Analisando essa realidade, ele lança os fundamentos de uma escola única inicial de cultura geral, com viés humanista, mas que equilibre o desenvolvimento para o trabalho técnico e intelectual (GRAMSCI, 1982, p. 118).

Portanto, compreendemos que a socialização do conhecimento científico, tecnológico, cultural e filosófico é uma condição necessária para o fortalecimento da classe trabalhadora na luta contra o capital. É urgente a tarefa de mobilização das massas para o exercício da política contra a burguesia e seus intelectuais. Tal enfrentamento só é possível se entrarmos na disputa dos aparelhos de hegemonia (FRIGOTTO, 2006, p. 277). Nesse sentido:

É preciso, como assinala Gramsci, a elevação moral e intelectual das massas. Por isso a agenda da luta da esquerda, independentemente de onde atue, tem que afirmar como estratégico e prioritário o direito da educação escolar básica (fundamental e média) unitária e politécnica e/ou tecnológica, que articule conhecimento científico, filosófico, cultural, técnico e tecnológico com a produção material e a vida social e política, para todas as crianças e os jovens. Articulada a essa formação básica está a formação técnico-profissional dos adultos, como um direito social de prosseguir se qualificando e como possibilidade de se inserir na produção dentro das novas bases científico-técnicas que the são inerentes. (FRIGOTTO, 2006, p. 278).

Considerando que a democratização da oferta de vagas na escola pública se deu de modo precarizado, há um cuidado necessário dos trabaIhadores frente à crescente democratização da oferta de educação profissional a partir dos anos 1990, pois, apesar de aparentemente suas reivindicações por educação estarem sendo atendidas, tal atendimento se dá na contramão dos reais interesses de emancipação da classe trabalhadora. Isso ocorre porque, ao invés da negação de "oportunidades", multiplica-se a oferta em projetos de formação totalmente desiguais. Estes, na maioria das vezes, apenas certificam os sujeitos sem, contudo, garantir o "domínio de conhecimentos necessários ao desenvolvimento de competências cognitivas 
complexas vinculadas a autonomia intelectual, ética e estética" (KUENZER, 2007, p. 1170-1171).

Em termos conjunturais, os programas de educação profissional, não sem contradições, constituem-se de propostas "ambivalentes de educação, que se caracterizam principalmente pela diferenciação de acesso às condições materiais necessárias ao bom desempenho" (OLIVEIRA, 2010, p. 351). Dito de outro modo, não são garantidas todas as condições necessárias para o pleno desenvolvimento pedagógico no processo educativo, isto é, não se oferta infraestrutura física e pedagógica adequada, como professores qualificados, laboratórios, bibliotecas, assistência estudantil, recursos tecnológicos etc. que atendam às necessidades reais dos alunos.

Já no que se refere ao aspecto estrutural, tratam-se de propostas pedagógicas dedicadas unicamente à educação profissional, ou seja, à formação de trabalhadores para o trabalho manual sem integração com a formação geral. Ou então, por outro lado, são precariamente articuladas, impedindo que a classe trabalhadora tenha pleno acesso ao conhecimento historicamente construído. Logo, a formação dos trabalhadores fundamentase na desigualdade tanto das condições materiais de estudo como também dos objetivos finais dos processos formativos, radicalizando a histórica dualidade estrutural da educação brasileira.

Assim, a partir do exposto, podemos desconfiar dos atuais programas de formação para o trabalho, pois estes não visam de fato a uma proposta pedagógica unitária e politécnica, em que se articule formação geral e formação para o trabalho para amplas massas de trabalhadores. Para estas, há um projeto de formação fragmentada, sem proposta real de elevação da escolaridade e acesso ao conhecimento científico, tecnológico, filosófico e cultural. A fim de apresentar a materialização dessa oferta de educação profissional precarizada, analisaremos o Pronatec e o seu contexto de criação, especificamente os rumos dados à educação profissional no Brasil a partir dos anos 1990 .

\section{O Pronatec como política social de formação profissional: contexto e retrocesso na socialização do conhecimento}

O Pronatec surge a partir do discurso empresarial de que não há, no Brasil, quantitativo suficiente de força de trabalho qualificada e que isso impede o nosso desenvolvimento econômico. Esse discurso, atrelado ao da "ineficiência" das escolas federais de educação profissional, foi também a tese central da Reforma da Educação Profissional nos anos 1990, ainda no Governo Fernando Henrique Cardoso (1995-2002). Nessa reforma, a educação profissional foi regulamentada pelo Decreto 2.208/1997 (BRASIL, 1997a), reforçando a já histórica dualidade presente desde a gênese de nosso sistema educacional. 


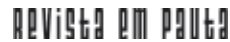

\} POLÍTICAS DE FORMAÇÃO PARA O TRABALHO - RAMOS, M. S.; STAMPA, I. \}

DOI: $10.12957 /$ REP.2016.27862

Com esse decreto efetivou-se a desvinculação entre a educação profissional e a formação de caráter propedêutico, flexibilizando, aligeirando e fragmentando a educação profissional para melhor responder às demandas de mercado de trabalho. No artigo $5^{\circ}$ deste decreto temos a seguinte redação: "A educação profissional de nível técnico terá organização curricular própria e independente do ensino médio, podendo ser oferecida de forma concomitante ou sequencial a este" (BRASIL, 1997a). Para Cêa (2006, p. 3), esse decreto:

Contribuiu para a institucionalização de um sistema paralelo de formação profissional que, embora pudesse se articular com o sistema regular de ensino (apenas concomitante ou sequencialmente, mas não de forma integrada), era dele prescindível. Tal desarticulação, presente na história da educação há tempos, vinha ocorrendo de forma paralela e, até certo ponto, marginal ao sistema educacional público. A partir de 1997, essa dualidade passa a ser uma orientação legal e uma prescrição oficial, a ponto da 'educação profissional' configurar-se, predominantemente, como um subsistema no interior do próprio sistema público de educação, voltado para a formação do trabalhador, sem a promoção da elevação dos níveis de escolaridade.

Diante disso, as redes estaduais de educação que mantinham escolas técnicas foram obrigadas a ofertar seus cursos apenas na forma concomitante ou subsequente ao ensino médio, ampliando, porém, a oferta de cursos profissionalizantes. Nesse processo, também sofreu grande ofensiva a Rede Federal de Educação Profissional Científica e Tecnológica, ou apenas Rede Federal, instituição de tradição na oferta de cursos que integram formação geral e profissional. A intenção inicial era extinguir a oferta de ensino médio na Rede Federal, sob a alegação de que ela deveria ser mais eficiente na formação profissional. Porém, houve resistência entre estudiosos da educação profissional, grupos de pesquisa, alunos, professores e técnicos administrativos da Rede Federal, fazendo com que o governo se limitasse a reduzir em 50\% a oferta de ensino médio (BRASIL, 1997b). O descumprimento desta determinação resultaria em diminuição nos repasses financeiros.

Nesse mesmo contexto, estava em vigor o Plano Nacional de Formação Profissional (Planfor), que ampliou a oferta de cursos de qualificação com baixa carga-horária, em caráter de treinamento, com pouca integração com a educação básica.

Assumindo o legado de Fernando Henrique Cardoso, o governo de Luiz Inácio Lula da Silva (2003-2010) trouxe grandes expectativas por mudanças estruturais na educação profissional, pois, em seu diálogo com os setores populares e acadêmicos, havia sido firmada a revisão do Decreto 2.208/97 (BRASIL, 1997a). Entretanto, o "novo" Plano Nacional de Qualificação (PNQ) criado no Governo Lula avançou muito pouco, política e pedagogicamente, frente às ações do Planfor, mantendo seus princípios e 


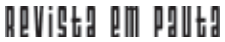

\} POLITICAS DE FORMAÇÃO PARA O TRABALHO - RAMOS, M. S.; STAMPA, I. \}

DOI: $10.12957 /$ REP.2016.27862

aprofundando a formação profissional para a informalidade e arranjos locais. Destaca-se, ainda, que a tão esperada integração com a educação básica não foi alcançada. De modo geral, as mudanças entre o Planfor e o PNQ trataram-se principalmente de adequações terminológicas ${ }^{8}$.

Não obstante, como resultado das pressões sociais exercidas por alguns segmentos, como os servidores e alunos da Rede Federal, dentre outros movimentos na sociedade civil, Lula, revogando o Decreto 2.208/ 1997 (BRASIL, 1997a), promulgou o Decreto 5.154/2004 (BRASIL, 2004). Este determinou que a educação profissional técnica de nível médio deveria ser desenvolvida de forma integrada, concomitante ou subsequente ao ensino médio. A forma integrada consiste na "fusão" entre ensino médio e ensino técnico, e nela encontraríamos maiores possibilidades de trocas didático-pedagógicas entre a formação geral e a formação profissional. Já no modo concomitante, a formação geral e a formação profissional tendem a ser desenvolvidas de forma estanque, não havendo qualquer relação entre ambas. Por fim, na modalidade subsequente, a educação profissional é oferecida posteriormente ao ensino médio àqueles que já concluíram este nível de ensino. Contudo, apesar de esse decreto ter aberto a possibilidade da oferta do ensino médio integrado à educação profissional, a antítese é evidenciada nas iniciativas de integrar a formação para o trabalho com a formação geral básica, em um contexto em que o conhecimento cada vez mais se torna importante instrumento de luta de classes.

A partir da análise de programas como o ProJovem e o Proeja, pesquisas já têm apontado contradições e limites da integração entre formação profissional e básica na ordem do capital, tanto no ensino fundamental quanto no ensino médio. Apesar de iniciativas pontuais que apresentam bons resultados, de modo geral, os principais entraves situam-se na ausência de critérios avaliativos sobre a qualidade dos cursos, na ausência de formação e de articulação entre os professores, nas altas taxas de evasão discente e docente, na ausência de recursos tecnológicos e de infraestrutura, na precariedade dos contratos de trabalho dos profissionais e no improviso na organização administrativa e pedagógica (OTRANTO, 2011; GOUVEIA, 2011; RIBEIRO, 2011; BLANCO, 2009).

As iniciativas de integração citadas acima, apesar de estarem cerceadas pelos limites de reprodução do capital, não podem ser desconsideradas como espaços formativos contraditórios, uma vez que elas abrem espaço de disputa pela hegemonia entre dois projetos de integração para a classe trabalhadora: a integração apenas formal e a integração real. Mas, para que esta disputa resulte em ganhos reais para a classe trabalhadora, faz-se necessário um amplo processo de reestruturação das instituições que a representam, como também a criação de estratégias que tornem mais compreensíveis as pautas e formas de luta para a ampla massa de traba-

${ }^{8}$ Para mais detalhes sobre as similaridades entre o Planfor e o PNQ, ver Jorge (2009). 
Ihadores. Precisaríamos de uma nova pedagogia de articulação da classe trabalhadora em torno de um novo projeto de sociedade. Além disso, tratase também de fortalecer tais instituições, para que estas tenham condições de disputar os recursos do Fundo de Amparo ao Trabalhador (FAT) ${ }^{9}$, que hoje tem sido tomado por Organizações Não Governamentais (ONGs) e por instituições que desenvolvem programas de qualificação profissional (FRIGOTTO, 2006, p. 267).

Como visto, a política de educação profissional vem, desde os anos 1990 até os dias atuais, oscilando entre avanços e permanências sob a ótica da classe trabalhadora. Já com o Pronatec, a classe dominante consegue aprofundar os retrocessos e as permanências, em detrimento dos pequenos avanços. Vejamos a proposta do programa.

O Pronatec foi criado em 26 de outubro de 2011 pelo Governo Federal, sancionado pela Lei 12.513/2011 (BRASIL, 2011) e, até junho de 2014, já havia alcançado a faixa de 7.341.047 matrículas (BRASIL, 2014a, p. 39). Ele constitui-se em um grande "guarda-chuva" que abriga diversas iniciativas de formação para o trabalho. Seu objetivo geral é democratizar o acesso à educação profissional no Brasil. Diferentemente do Planfor e do PNQ, cujo organizador era o Ministério do Trabalho e Emprego (MTE), para o desenvolvimento do programa foi criado um arranjo político-institucional que centraliza a oferta de cursos no Ministério da Educação (MEC). Os demais ministérios atuam na condição de demandantes, enquanto o MEC é o ofertante de cursos.

Os pilares do Pronatec são: a) a expansão da Rede Federal; b) a ampliação da oferta da educação profissional integrada ao ensino médio nas redes estaduais; c) o fortalecimento da Rede de Educação Profissional e Tecnológica a Distância (Rede e-Tec Brasil) em sua oferta de cursos de formação inicial e continuada; e d) a parceria com o "Sistema $S^{10 "}$ e outras instituições privadas (BRASIL, 2014a). Em princípio, a democratização da oferta de educação profissional poderia ser entendida como um ganho para a classe trabalhadora; entretanto, é importante questionar que tipo de educação profissional está sendo democratizada.

O público-alvo é composto por: estudantes do ensino médio (regular e Educação de Jovens e Adultos - EJA) da rede pública de ensino; trabalhadores rurais (agricultores familiares, silvicultores, aquícolas, extrativistas) e pescadores; beneficiários titulares e dependentes de programas federais de transferência de renda; estudantes que tenham cursado o ensino médio em instituições privadas com bolsa integral ou em instituições públicas; trabalhadores reincidentes na solicitação do seguro-desemprego

\footnotetext{
${ }^{9}$ Os estudos de Cêa (2004) e Amaral (2005) nos ajudam a compreender a disputa pelo FAT tanto pelos empresários como por instituições representativas dos trabalhadores.

${ }^{10}$ Nome pelo qual ficou convencionado o conjunto das instituições de interesse de categorias profissionais: Senar; Senac; Sesc; Senai; Sesi; Sebrae. A criação desses organismos remonta a meados da década de 1940 e apenas quatro delas (Sescoop, Senar, Sest e Senat) foram instituídas após a Constituição Federal de 1988.
} 


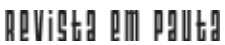

\} POLÍTICAS DE FORMAÇÃO PARA O TRABALHO - RAMOS, M. S.; STAMPA, I. \}

DOI: $10.12957 /$ REP.2016.27862

no prazo de 10 anos; pessoas com deficiência; povos indígenas; comunidades quilombolas e outras comunidades tradicionais; jovens em cumprimento de medidas socioeducativas; e públicos prioritários dos programas do Governo Federal. Além dos grupos citados acima, o programa abrange também os trabalhadores domésticos, trabalhadores não remunerados, trabalhadores autônomos e trabalhadores para o próprio consumo, independentemente de estarem ou não exercendo alguma atividade (BRASIL, 2011; BRASIL, 2013a).

O Pronatec se desenvolve por meio de um fomento chamado de "Bolsa Formação". Este se subdivide em dois tipos: Bolsa Formação Estudante e Bolsa Formação Trabalhador. A Bolsa Formação Estudante tem como objetivo:

Formar profissionais para atender às demandas do setor produtivo e do desenvolvimento socioeconômico e ambiental do País; contribuir para a melhoria da qualidade do Ensino Médio público, por meio da articulação com a Educação Profissional; ampliar e diversificar as oportunidades educacionais aos estudantes, por meio do incremento da formação técnica de nível médio. (BRASIL, 2013b, art. 17 - grifo nosso).

Essa modalidade oferta cursos técnicos de nível médio, de no mínimo 800h, para alunos das Redes Estaduais de ensino no contraturno da jornada escolar. O programa não define regras para o processo de avaliação e escolha dos alunos atendidos, pelo contrário, as regras são estabelecidas pelas secretarias estaduais de educação. No Estado do Rio de Janeiro, por exemplo, o processo se dá por meio do Sistema de Avaliação da Educação do Estado do Rio de Janeiro (Saerj). Os alunos com as maiores notas são selecionados.

Convém lembrar que o ensino médio é a última etapa da educação básica, que tem como finalidade consolidar os conhecimentos adquiridos no ensino fundamental, preparar para o exercício da cidadania e para o trabalho, com foco na adaptação do aluno às novas configurações ocupacionais, desenvolver o pensamento crítico, a autonomia e ajudar o aluno a compreender os fundamentos científicos e tecnológicos dos processos produtivos. Já a educação profissional técnica de nível médio tem a função de preparar o aluno para o exercício de profissões técnicas (BRASIL, 1996, art. 35-36).

A defesa da integração entre essas duas modalidades de educação tem como horizonte a abertura de possibilidades, ainda que no sistema capitalista, de atrelar a formação para o trabalho, de acordo com o atual patamar de desenvolvimento científico e tecnológico, com a formação política e social que possibilite o processo de conscientização da classe trabalhadora. Trata-se, assim, de um processo que aponta para a minimização da dualidade estrutural da educação brasileira, constituindo-se como "travessia" 


\section{hevigtg aाm pguttg}

\} POLÍTICAS DE FORMAÇÃO PARA O TRABALHO - RAMOS, M. S.; STAMPA, I. \}

DOI: $10.12957 /$ REP.2016.27862

para a construção da escola unitária, inspirada no referencial marxista (CIAVATTA; RAMOS; FRIGOTTO, 2005).

No entanto, apesar da possiblidade aberta pelo Decreto 5.154/ 04 (BRASIL, 2004), a "travessia" citada pelos autores tem sido impossibilitada, dentre outros fatores, pelo fato de o ensino médio integrado à educação profissional não ser um sistema padrão no Brasil, mas apenas uma dentre outras possibilidades, fazendo com que programas como o Pronatec substituam investimentos estruturais para a oferta de cursos integrados. Por outro lado, a mera combinação entre formação geral e profissional não significa, por si só, um projeto educativo anticapitalista, mas pode contribuir significativamente para a instrumentalização dos trabalhadores na luta contra o capital.

Do rol de objetivos da Bolsa Formação Estudante, anunciados pela lei que cria o Pronatec, destacamos o de "contribuir para a melhoria da qualidade do Ensino Médio Público". Essa intenção poderia ser materializada através de maiores investimentos no programa Brasil Profissionalizado, para que as redes estaduais pudessem ampliar as vagas em educação profissional integrada ao ensino médio ou através da ampliação das vagas de ensino médio integrado à educação profissional na Rede Federal. Certamente, ambas as ações efetivariam a real melhoria do ensino médio público. No entanto, se compararmos as transferências governamentais desde a criação do programa até o ano de 2014, por exemplo, perceberemos que é o Sistema S, e não o ensino médio público, que tem se beneficiado com o fundo público no âmbito do Pronatec. Vejamos

Transferências anuais aos parceiros ofertantes de 2011 a maio de 2014 (R\$).

\begin{tabular}{|c|c|c|c|c|c|}
\hline $\begin{array}{l}\text { Rede de } \\
\text { Ensino }\end{array}$ & 2011 & 2012 & 2013 & 2014 & $\begin{array}{c}\text { Total por Rede de } \\
\text { Ensino }\end{array}$ \\
\hline SNA & $208.261 .704,50$ & $1.054,161.444,18$ & $2.065 .021 .070,00$ & $1.200 .822 .145,00$ & $4.528 .266 .363,68$ \\
\hline $\begin{array}{l}\text { Rede } \\
\text { Federal }\end{array}$ & $39.827 .005,00$ & $338789.930,90$ & $742.501 .736,80$ & $193.924 .454,25$ & $1.315 .043 .126,95$ \\
\hline $\begin{array}{l}\text { Rede } \\
\text { Estadual }\end{array}$ & (n...... & $92.648 .000,00$ & $228.482 .150,00$ & $83.393 .000,00$ & $404.523 .150,00$ \\
\hline $\begin{array}{l}\text { Rede } \\
\text { Municipal }\end{array}$ & ........ & $\ldots$ & $14.681 .000,00$ & $3.380 .000,00$ & $18.061 .000,00$ \\
\hline $\begin{array}{l}\text { Rede } \\
\text { Provada }\end{array}$ & ........ & $\ldots$ & $51.681 .163,63$ & $138.113,463,01$ & 189.794 .626 .64 \\
\hline Total anual & $248.088 .709,50$ & $1.485 .599 .376,08$ & $3.102 .367 .120,43$ & $1,619.633 .062,26$ & $6.455 .688 .267,27$ \\
\hline
\end{tabular}

Fonte: (BRASIL, 2014b). Quadro reeditado pelos autores.

O quadro acima nos ajuda a compreender que o objetivo anunciado pela lei - melhorar a qualidade do ensino médio público - não corresponde à real implantação do programa, pois partimos do princípio de que melhorias na educação dependem diretamente dos recursos destinados para a área. Ao contrário, no Pronatec, tanto a Rede Federal como as Redes Estaduais são secundarizadas com relação ao Sistema S, o qual, 


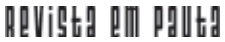

\} POLITICAS DE FORMAÇÃO PARA O TRABALHO - RAMOS, M. S.; STAMPA, I. \}

DOI: $10.12957 /$ REP.2016.27862

no contexto do programa, é tratado como instituição pública, sendo dispensado até mesmo de convênios.

Historicamente, o Sistema S se constituiu como um conjunto de instituições educativas que entraram na disputa pela formação do trabalhador de modo interessado. São instituições particularistas que disputam o fundo público para a formação para o trabalho de acordo com os interesses da burguesia ${ }^{11}$. Nesse sentido, o Pronatec não apresenta propostas claras de melhoria do ensino médio público.

Em contrapartida, as instituições que compõem a Rede Federal precisam ampliar as vagas, sem a ampliação real de sua estrutura física e pedagógica. Algumas pesquisas sobre a materialização do Pronatec têm sido realizadas. Dentre as quais, podemos destacar a de Ramos (2014) que, analisando três campi de uma das instituições que compõem a Rede Federal, constatou que, para os alunos do programa, o governo cria uma estrutura paralela sem ampliação real da estrutura física e pedagógica, como número de profissionais, laboratórios, bibliotecas e salas de aula.

Elencamos, a seguir, os principais problemas identificados por Ramos (2014): a) regimento diferenciado para os alunos do Pronatec, possibilitando apenas uma reprovação sob pena de perder a bolsa; b) indefinição sobre os pagamentos do período dedicado às atividades de recuperação, gerando grandes problemas para o processo de avaliação; c) alocação do Pronatec no horário de planejamento dos docentes, gerando conflito de horários; d) tratamento diferenciado para os alunos, por conta do acesso diferenciado; e) possibilidade de contrato temporário para lecionar no programa em caso de não aceitação dos profissionais da Rede Federal; f) no caso de aceitação dos profissionais da Rede Federal, o Pronatec entra como hora extra, com alta rotatividade, dificultando a criação de vínculos com os alunos; g) atraso no pagamento das bolsas, aumentando o número de alunos evadidos por falta de recursos financeiros para se alimentar e se locomover; e h) nenhuma articulação com o ensino médio.

A Bolsa Formação Estudante revela uma burguesia que historicamente se vale mais da coerção que do consenso, pois não tem sido capaz de atender aos interesses históricos da classe trabalhadora organizada no que se refere à superação da dualidade do sistema educacional brasileiro. As estratégias de dominação se dão de modo conservador, pois até os dias de hoje o ensino médio não é uma realidade na vida de milhares de brasileiros, muito menos o ensino integrado com a educação profissional.

Dados da Pesquisa Nacional por Amostra de Domicílios (Pnad) de 2015 apontam que, no Brasil, apenas $26 \%$ das pessoas com idade acima de 25 anos possui ensino médio completo (IBGE, 2015). Dados importantes também são apresentados na Sinopse Estatística da Educação Básica de 2015, que mostra que as matrículas em cursos de ensino médio integrado

${ }^{11}$ Para melhor compreensão da atuação do Sistema S, ver Rodrigues (1998). 


\section{hevigtg aाm pguttg}

\} POLÍTICAS DE FORMAÇÃO PARA O TRABALHO - RAMOS, M. S.; STAMPA, I. \}

DOI: $10.12957 /$ REP.2016.27862

ao técnico somaram 391.766, enquanto que os cursos de ensino médio de formação geral alcançaram 7.590.465 matrículas (INEP, 2016). Apesar de reconhecermos os avanços na ampliação de matrículas em ambas as modalidades durante os governos do Partido dos Trabalhadores (PT), ainda é evidente o atraso na oferta de ensino médio, bem como na integração com a educação profissional.

Agora vejamos os objetivos da Bolsa Formação Trabalhador:

Formar profissionais para atender às demandas do setor produtivo e do desenvolvimento socioeconômico e ambiental do País; ampliar as oportunidades educacionais por meio da Educação Profissional e tecnológica com a oferta de cursos de formação profissional inicial e continuada; incentivar a elevação de escolaridade; e integrar ações entre órgãos e entidades da administração pública federal e entes federados para a ampliação da Educação Profissional e tecnológica. (BRASIL, 2013b, art. 38 - grifo nosso).

Através da Bolsa Formação Trabalhador, em que são ofertados apenas os cursos de Formação Inicial e Continuada (FIC), o MEC atende a demandas de diversos ministérios, com destaque para os trabalhadores demitidos, encaminhados pelo MTE, e para os beneficiários de programas sociais, encaminhados pelo Ministério do Desenvolvimento Social (MDS). Além desses, o MEC também contempla os estudantes do ensino médio, da modalidade EJA, das redes estaduais de ensino.

Os cursos do Pronatec FIC devem ter, no mínimo, 160h e caracterizam-se: a) pela ausência de diálogo com a educação básica; b) pela formação aligeirada com certificação parcial dentro de uma área do conhecimento; c) pelo ensino de saberes que, de modo geral, poderiam ser apreendidos no próprio processo de trabalho; d) pela formação sem aprofundamento teórico para o trabalho simples; e) pela baixa escolaridade como pré-requisito; e f) por não promover a elevação da escolaridade dos trabalhadores (RAMOS, 2014).

A fim de esclarecer a concepção de formação que norteia os cursos do Pronatec FIC, e como ela fere a necessidade que a classe trabalhadora tem de que o conhecimento seja socializado como possibilidade de emancipação, trazemos a seguir a fala de uma supervisora de curso:

Tem muitos professores que são muito rigorosos. Né? Então, nem sempre aceitam muito bem a ideia de quê... é... ela é camareira. Ela tá se formando pra ser camareira, mas ela fala errado. Ela troca, sei lá, o ' $r$ ' pelo ' $I$ '. E aí é difícil pro professor entender que isso não vai influenciar na parte operacional dela de camareira. Se ela consegue se comunicar, escrever mesmo que errado, ela consegue se desenvolver... ser uma boa camareira. Ser uma boa camareira não vai 
estar condicionado à forma como ela escreve ou que ela fala, mas como que ela faz um envelopamento de cama, se ela sabe a diferença entre limpar e higienizar e outros aspectos (sic). (RAMOS, 2014, p. 114).

Mesmo propondo-se a ampliar as oportunidades educacionais, para nós, o Pronatec FIC tem como objetivo real "produzir o pacote de competências adequadas à formação do cidadão produtivo ajustado técnica e socialmente às demandas do capital. Um cidadão que acredite que a ele não compete ser sujeito político" (FRIGOTTO, 2006, p. 266). O importante no currículo desses cursos é garantir que o trabalhador saiba fazer bem o seu trabalho, não necessitando da elaboração de novos saberes que the permitam compreender a sua situação de classe. Dentro do mesmo exemplo dado pelo supervisor de curso antes citado, entendemos que, além de envelopar a cama, a camareira deve conseguir compreender por qual razão ela é camareira e o seu patrão é dono do hotel, ou seja, compreender o seu lugar na divisão social do trabalho. Além disso, ela deve saber ler e escrever bem, ler não apenas as palavras, decodificando, mas "ler o mundo", indo além de sua aparência fenomênica e compreendendo as suas raízes.

No que tange às ações destinadas aos trabalhadores que acionam o Programa Seguro-Desemprego, atualmente a matrícula em um curso do Pronatec FIC tem sido exigida do trabalhador que solicita o seguro pela segunda vez no prazo de 10 anos. Cabe ao MTE enviar ao MEC informações sobre as características desses trabalhadores, para subsidiar as atividades de formação dos mesmos. O trabalhador só ficará desobrigado de realizar o curso em duas hipóteses: se não houver em seu município ou em município limítrofe a oferta de curso compatível com seu perfil, ou se ele comprovar matrícula e frequência em outro curso FIC com carga horária igual ou superior a $160 \mathrm{~h}$, contanto que o curso se desenvolva no mesmo período em que o trabalhador esteja recebendo as parcelas do seguro (BRASIL, 2012).

Apesar de reconhecermos a deficiência educacional que há em nosso país, fruto da precariedade com que se constituiu e democratizou nosso sistema de educação, não compactuamos com a ideia de que o desemprego seja reflexo da baixa qualificação dos trabalhadores. Para nós, tratase de um problema estrutural inerente à lógica capitalista, impossível de ser resolvido com cursos de qualificação. Se fosse de outro modo, não teríamos engenheiros, advogados e profissionais altamente qualificados, porém desempregados.

Dito isto, compreendemos que o atrelamento direto entre demissão e qualificação e a obrigatoriedade de realizar um curso de qualificação para ter acesso ao Programa Seguro-Desemprego sugere um culpado - o trabalhador - e converte a qualificação profissional em obstáculo para acessar um direito social. Só nos anos de 2014 e 2015, 9.328 trabalhadores 


\section{hevigtg aाm pguttg}

\} POLÍTICAS DE FORMAÇÃO PARA O TRABALHO - RAMOS, M. S.; STAMPA, I. \}

DOI: $10.12957 /$ REP.2016.27862

foram impedidos de receber as parcelas do Programa Seguro-Desemprego ${ }^{12}$ (BRASIL, 2016). Mesmo estando na legislação desse programa o apoio na "busca e na manutenção" do emprego, entendemos que isso não se resume à matrícula em um curso de qualificação de forma compulsória, pois, desse modo, todas as variáveis do desemprego estariam se resumindo à qualificação profissional.

Enquanto o MEC atua na organização dos cursos através de sua rede de educação profissional, o MTE, por meio do Sistema Nacional de Emprego (Sine) e demais postos de atendimento ao trabalhador, tem a tarefa de executar o Programa Seguro-Desemprego, por meio do acolhimento inicial, orientação, intermediação da força de trabalho para vagas existentes e encaminhamento para um curso de qualificação profissional do Pronatec. Entretanto, estudos como o de Magalhães (2015) mostram que, pela forma como estão organizadas as agências, o atendimento tem sido rápido e despersonalizado, o que, para nós, torna inviável um processo de orientação que considere os anseios e as trajetórias profissionais e escolares dos trabaIhadores.

No Instituto Federal de Educação, Ciência e Tecnologia do Rio de Janeiro (IFRJ), realizamos pesquisa com 20 trabalhadores que, para receberem as parcelas do Programa Seguro-Desemprego, precisaram se matricular no Pronatec. Ao serem questionados sobre a orientação para a escolha dos cursos, $80 \%$ dos alunos pesquisados responderam que não tiveram qualquer orientação. No entanto, $65 \%$ afirmaram terem escolhido o curso por afinidade com a área e apenas 10\% afirmaram ter escolhido o curso porque era a única opção. Os demais apresentaram motivações diversas, como proximidade da residência e tempo de duração do curso. Todavia, ao compararmos esses dados com a fala de um dos coordenadores do Pronatec no IFRJ, fica evidente a fragilidade do programa nessa questão:

Tem pessoas que se inscreveram no curso e o curso não tem nada a ver com toda a trajetória profissional deles e isso daí não vai somar em nada para a qualificação profissional dele. Vamos dizer assim, nós temos, por exemplo, hoje, uma motorista de ônibus. Ela não evadiu, a gente conseguiu segurar ela. Mas a chance dela evadir seria enorme, pois um curso, porque um curso de, por exemplo, que ela está fazendo de agente de resíduos sólidos. [...] isso não é usado na carreira dela como motorista. Ela nunca vai usar isso, então, e ela foi praticamente obrigada pelo ministério a escolher. (RAMOS, 2014, p. 119-120).

O relato acima nos permite concluir que, diante do desemprego, os trabalhadores tendem a passar por um processo de reconversão profis-

\footnotetext{
${ }^{12}$ Engloba trabalhadores desistentes, evadidos, os que não efetivam matrícula, os que se recusam a participar e os reprovados nos cursos do Pronatec. Nesses casos os trabalhadores não puderam receber as parcelas do Programa Seguro-Desemprego.
} 


\section{meVistg am palto}

\} POLÍTICAS DE FORMAÇÃO PARA O TRABALHO - RAMOS, M. S.; STAMPA, I. \}

DOI: $10.12957 /$ REP.2016.27862

sional obrigatório, que os leva para uma área totalmente diferente da que atuavam antes ou na qual têm formação. A reconversão profissional pode ser uma mudança de perfil ou de ocupação no mesmo ramo ou em outro ramo da economia. Pode ainda se dar do mercado formal para o informal, e também no perfil educacional: "reconversão de um baixo nível educacional para um nível mínimo de educação" (SOUZA; SANTANA; DELUIZ, 1999 , p. 70). Essa migração seria questionável, porém minimamente tolerável, se não fosse compulsória. Percebe-se ainda que a integração entre o MTE e o MEC não tem sido satisfatória quanto ao direcionamento do trabalhador para um curso de qualificação que tenha significado real para ele. Conforme aponta o mesmo coordenador do Pronatec no IFRJ:

[...] a reclamação grande que nossos alunos têm é que eles chegavam no Ministério de Trabalho, aí eles entregavam uma lista: - oh, escolhe aí! Aí o cara começava a ler, mal ele começava a ler: - Oh, escolhe logo! Precisa andar. Tem outro na fila. Vamos logo, vamos logo! (RAMOS, 2014, p. 119).

Porém, de acordo com as regras do Pronatec, não é o trabalhador quem deve se adequar aos cursos. Cabe ao MTE "encaminhar ao Ministério da Educação informações sobre as características dos trabalhadores beneficiários do seguro-desemprego para subsidiar as atividades de formação e qualificação profissional desenvolvidas para atendimento desse público" (BRASIL, 2011).

Contudo, importa esclarecer que mesmo que as agências de atendimento tivessem condições para acolher e orientar os trabalhadores, num processo mais personalizado, a política de encaminhamento estaria ainda restrita a opções de cursos, pois o padrão Pronatec para o seguro-desemprego é de cursos de curta duração. O programa se apresenta engessado num único modelo, mesmo atendendo a um público diverso, formado por alunos oriundos de múltiplas famílias ocupacionais e com níveis de escolaridade diferentes.

Por fim, o condicionamento do Programa Seguro-Desemprego ao Pronatec se mostra inviável em nosso país pelo atraso histórico na expansão da educação, além da ausência de uma rede pública de educação profissional ampla, diversificada e adequada aos determinantes econômicos locais e regionais.

\section{Considerações finais}

A partir do exposto, pode-se concluir que a socialização do conhecimento para a classe trabalhadora não pode ser vista como um fim e sim como um meio, pois, apesar de não ser suficiente para pôr fim ao sistema capitalista, essa ação é indispensável na luta dos trabalhadores contra 


\section{hevigtg aाm pguttg}

\} POLÍTICAS DE FORMAÇÃO PARA O TRABALHO - RAMOS, M. S.; STAMPA, I. \}

DOI: $10.12957 /$ REP.2016.27862

este sistema. Trata-se de compreender a educação como processo contraditório, podendo servir não só como dominação burguesa, mas também como meio de luta e disputa pela hegemonia. Logo, dependendo do grau de interferência da classe trabalhadora na sociedade civil, outros projetos formativos, mais próximos do que deseja esta classe, podem se concretizar.

Sem abandonar o ideal revolucionário, precisamos explorar todas as possibilidades de disputa pela hegemonia no sistema capitalista como espaço de emancipação e construção da consciência de classe. Entendemos que o saber é produzido socialmente no conjunto das relações sociais. No entanto, a classe trabalhadora tem sido apartada desse saber, não recebendo, por meio da escola dedicada a ela, as ferramentas necessárias à elaboração e sistematização do conhecimento. Além disso, o saber elaborado é um meio de produção, sendo a sua socialização o princípio da socialização dos meios de produção (SAVIANI, 2012a).

Podemos observar esse movimento por meio do Pronatec, que democratiza o acesso às vagas em educação profissional sem dar às camadas populares o instrumental necessário para a luta social e política, evidenciando que as ações governamentais estão direcionadas somente para a ampliação de oportunidades, mesmo que essas oportunidades sejam desiguais. Apesar disso, "a superação do capitalismo somente pode ser atingida pela luta de classes, partindo da identificação e da exploração, no plano histórico, de suas insanáveis e cada vez mais profundas contradições" (FRIGOTTO, 2006, p. 244).

É preciso, então, que as contradições do Pronatec sejam identificadas e exploradas ao extremo. Certamente muitos alunos que hoje cursam o Pronatec nunca teriam entrado em uma escola técnica federal se não fosse por meio do programa. No entanto, esses alunos não estão entrando da mesma forma que os demais, pois para eles cria-se uma estrutura precarizada, que em nada se articula com a formação geral. De alguma forma, programas como o Pronatec abrem, no mínimo, a possibilidade de discussão e confronto entre o projeto que está posto e o que a classe trabalhadora deseja. Eis o paradoxo! 


\section{Referências}

AMARAL, A. S do. Qualificação dos trabalhadores e estratégia de hegemonia: o embate de projetos classistas. Tese (Doutorado) - Programa de Pós-Graduação em Serviço Social, Universidade Federal do Rio de Janeiro, 2005.

BLANCO, D. M. À luz do dia nem todos os gatos parecem pardos: percepções de jovens sobre os limites e possibilidades do ProJovem. Dissertação (Mestrado) - Programa de Pós-Graduação em Sociologia, Universidade Federal do Rio Grande do Sul, 2009. Disponível em: <https://www.lume. ufrgs.br/bitstream/handle/10183/25483/000736161. pdf? sequence=1 >. Acesso em: 10 maio. 2015.

BRASIL. Lei n 5.692 de 11 de agosto de 1971. Fixa as diretrizes e bases para o ensino de $1^{\circ} \underline{\text { e }} 2^{\circ}$ graus e dá outras providências. Brasília, Presidência da República, 1971. Disponível em: <http://www010.dataprev.gov.br/sislex/ paginas/42/1971/5692.htm>. Acesso em: 1 maio. 2015.

. Lei 9.394 de 20 de dezembro de 1996. Estabelece as diretrizes e bases da educação nacional. Brasília, DF, 1996. Disponível em: <http:// portal.mec.gov.br/ arquivos/pdf/ldb.pdf>. Acesso em: 28 jan.2015.

. Decreto 2.208 de 17 de abril de 1997. Regulamenta o § 2 ㅇ do art. 36 e os art. 39 a 42 da Lei no 9.394 de 20 de dezembro de 1996, que estabelece as diretrizes e bases da educação nacional. Brasília, 1997a. Disponível em: <http://www.planalto.gov.br/ ccivil_03/decreto/D2208.htm >. Acesso em: 3 abr. 2015.

. Portaria Ministerial no 646 de 14 de maio de 1997. Regulamenta a implantação do disposto nos artigos 39 a 42 da Lei Federal no 9.394/96 e no Decreto Federal no 2.208/97 e dá outras providências. Brasília, DF, 1997b. Disponível em: <http://portal.mec.gov.br/setec/arquivos/pdf/PME C646_97.pdf >. Acesso em: 1 set. 2015.

Decreto 5.154 de 23 de julho de 2004. Regulamenta o § 2o do art. 36 e os art. 39 a 41 da Lei no 9.394 de 20 de dezembro de 1996, que estabelece as diretrizes e bases da educação nacional e dá outras providências. Brasília, DF, 2004. Disponível em: <http://www.planalto. gov.br/ccivil_03/ ato2004-2006/2004/decreto/d5154.htm>. Acesso em: 2 set. 2013.

. Lei 12.513 de 26 de outubro de 2011. Instituiu o Programa Nacional de Acesso ao Ensino Médio e Emprego (Pronatec); altera as leis no 7.998 de 11 de janeiro de 1990, que regula o programa do seguro-desemprego, o abono salarial e instituiu o Fundo de Amparo ao Trabalhador (FAT), $\mathrm{n}^{\mathrm{o}}$ 8.212 de 24 de julho de 1991, que dispõe sobre a organização da Seguridade Social e instituiu o Plano de Custeio, no 10.260 de 12 de julho de 2001, que dispõe sobre o fundo de financiamento ao estudante do Ensino Superior 


\section{hevigtg aाm pguttg}

\} POLÍTICAS DE FORMAÇÃO PARA O TRABALHO - RAMOS, M. S.; STAMPA, I. \}

DOI: $10.12957 /$ REP.2016.27862

e no 11.129 de 30 de junho de 2005, que institui o 194 Programa Nacional de Inclusão de Jovens (ProJovem); e dá outras providências. Brasília, DF, 2011. Disponível em: <http://www.planalto.gov.br/ccivil_03/_ato20112014/2011/lei/l12513.htm>. Acesso em: 24 mar. 2015.

BRASIL. Decreto no 7.721 de 16 de abril de 2012. Dispõe sobre o condicionamento do recebimento da assistência financeira do Programa de Seguro Desemprego à comprovação de matrícula e frequência em curso de formação inicial e continuada ou de qualificação profissional, com carga horária mínima de cento e sessenta horas. Brasília, DF, 2012. Disponível em: <http:/ /pronatec.mec.gov.br/images/stories/pdf/decreto_7721.pdf>. Acesso em: 19 jan. 2013.

. MEC. Portaria no 168 de 7 de março de 2013. Dispõe sobre a oferta da Bolsa-Formação no âmbito do Programa Nacional de Acesso ao Ensino Técnico e Emprego - Pronatec, de que trata a Lei nº12.513 de 26 de outubro de 2011, e dá outras providências. Brasília, DF, 2013a Disponível em: <http://www.desenvolvimento.gov.br/arquivos/dwnl_1365533679.pdf>. Acesso em: 10 jan. 2012.

. MEC. Pronatec 2011-2013. Brasília, 2013b. Disponível em: <http:/ /www.epsjv.fiocruz.br/upload/doc/Pronatec-execucaoOfertantes-25-1113_v3.pdf>. Acesso em: 29 mai. 2015.

. MEC. Objetivos e iniciativas do Pronatec. Apresenta os objetivos e as iniciativas do Pronatec. Brasília, DF, 2014a. Disponível em: <http://pro natec.mec.gov.br/institucional/objetivos-e-iniciativas $>$. Acesso em: 3 out. 2013.

. TCU. Relatório de auditoria anual de contas. Brasil, 2014b. Disponível em: <http://portal.mec.gov.br/index.php?option=com_doc man\&task=doc_download\&gid=16416\&ltemid=>. Acesso em: 5 jun. 2015.

. MTE. Resposta do Ministério do Trabalho e Emprego por meio da Lei de Acesso à Informação. Serviço de Informação ao Cidadão (SIC) do TEM. Brasília, DF, 2016. Protocolo n. 23480.011783/2016-72. Resposta em 5 jul. 2016.

CÊA, G. S dos S. A qualificação profissional como instrumento de regulação social: do Planfor ao PNQ In: 27ํㅡ REUNIÃO ANUAL DA ANPED - GT Trabalho e educação, 2004. Disponível em: <http://www.anped.org.br/sites/ default/files/t099.pdf>. Acesso em: 10 nov. 2016.

. A reforma da educação profissional e o ensino médio integrado: tendências e riscos. In: 29a REUNIÃO DA ANPED - GT Trabalho e educação, 2006. Disponível em: <http://29reuniao.anped.org.br/trabalhos/ trabalho/GT09-2565-Int.pdf>. Acesso em: 25 nov. 2015.

COUTINHO, C. N. Gramsci: um estudo sobre seu pensamento político. Rio de Janeiro: Campus, 1989. 


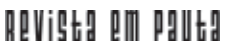

\} POLÍTICAS DE FORMAÇÃO PARA O TRABALHO - RAMOS, M. S.; STAMPA, I. \}

DOI: $10.12957 /$ REP.2016.27862

CERQUEIRA FILHO, G. A questão social no Brasil: crítica do discurso político. Rio de Janeiro: Civilização Brasileira, 1982.

COUTINHO, C. N.; TEIXEIRA, A. de P. (Org.). Ler Gramsci, entender a realidade. Rio de Janeiro: Civilização Brasileira, 2003.

DIAS, E. F. A liberdade (im)possível na ordem do capital: reestruturação produtiva e passivização. Textos didáticos. Campinas: Unicamp, 1999.

FERNANDES, F. Educação e sociedade no Brasil. São Paulo: Dominus/ Editora da Universidade de São Paulo (Edusp), 1966.

. Capitalismo dependente e classes sociais na América Latina. Rio de Janeiro: Zahar, 1975.

. O que é revolução. São Paulo: Editora Brasiliense, 1984.

. Nova República? Rio de Janeiro: Zahar, 1986.

FRIGOTTO, G. Fundamentos científicos e técnicos da relação trabalho e educação no Brasil de hoje. In: JÚLIO, C. F. L.; LÚCIA, N.; Lúcia M. W. (Org.). Fundamentos da educação escolar do Brasil contemporâneo. Rio de Janeiro: Editora Fiocruz, 2006.

FRIGOTTO, G.; CIAVATTA, M.; RAMOS, M. (Org.). Ensino médio integrado: concepção e contradições. São Paulo: Cortez Editora, 2005.

GOUVEIA, F. P. de S. Caminhos e descaminhos da implantação da educação de jovens e adultos no Instituto Federal de Educação Ciência e Tecnologia do Rio de Janeiro. Dissertação (Mestrado) - Programa de Pós-Graduação em Educação, Universidade Federal Rural do Rio de Janeiro, 2011, mimeo.

GRAMSCI, A. Os intelectuais e a organização da cultura. Campus: Rio de Janeiro, 1982.

. Cadernos do cárcere. Os intelectuais, v. 2. O princípio educativo. Jornalismo. Rio de Janeiro: Civilização Brasileira, 2001.

IAMAMOTO, M. V. O Serviço Social na contemporaneidade: trabalho e formação profissional. São Paulo: Cortez, 1998.

IANNI, O. A questão social. Revista da USP, São Paulo, out./nov./dez. 1989.

IBGE. INSTITUTO BRASILEIRO DE GEOGRAFIA E ESTATíSTICA. Pesquisa Nacional por Amostra de Domicílios Contínua (Pnad) - dados harmonizados, 2015. Disponível em: <http://www.ibge.gov.br/home/estatistica/populacao/ trabalhoerendimento/pnad2015/default_indicadores_harmonizados.shtm>. Acesso em: 3 dez. 2016.

INEP. INSTITUTO NACIONAL DE ESTUDOS E PESQUISAS EDUCACIONAIS ANÍSIO TEIXEIRA. Sinopse Estatística da Educação Básica 2015. Brasília: Inep, 2016. Disponível em: <http://portal.inep.gov.br/basica-levan tamentos-acessar>. Acesso em: 30 nov. 2016. 


\section{hevigtg aाm pguttg}

\} POLÍTICAS DE FORMAÇÃO PARA O TRABALHO - RAMOS, M. S.; STAMPA, I. \}

DOI: $10.12957 /$ REP.2016.27862

JORGE, T. A. da S. Políticas públicas de qualificação profissional no Brasil: uma análise a partir do Planfor e do PNQ. Tese (Mestrado) - Programa de Pós-Graduação em Educação da Universidade Federal de Minas Gerais, 2009.

KUENZER, A. Z. Da dualidade assumida à dualidade negada: o discurso da flexibilidade justifica a inclusão excludente. Revista Educação \& Sociedade, Campinas: Cedes, n. 100, 2007. Disponível em: <http://www.scielo.br/ pdf/es/v28n100/a2428100.pdf>. Acesso em: 3 jan. 2015.

MAGALHÃES, S. M. de O. Reincidência do trabalhador no Programa Seguro-Desemprego: o caso dos trabalhadores atendidos pelo Sine e o papel dos agentes de atendimento na implementação do programa no Distrito Federal. Dissertação (Mestrado) - Programa de Pós-Graduação em Educação da Universidade de Brasília, 2015. Disponível em: <https://sucupira.capes. gov.br/sucupira/public/consultas/coleta/trabalhoConclusao/viewTrabalho Conclusao.jsf?popup=true\&id_trabalho=2896839>. Acesso em: 1 set. 2016.

MARX, K. Crítica do Programa de Gotha. São Paulo: Boitempo Editora, 2012.

MARX, K.; ENGELS, F. A ideologia alemã. São Paulo: Boitempo Editorial, 2007.

MELLO, A. F. de. Mundialização e política em Gramsci. São Paulo: Cortez, 1996.

OLIVEIRA, D. A. Educação básica gestão e da pobreza. Petrópolis: Editora Vozes, 2010.

OTRANTO, C. R. A política de educação profissional do Governo Lula: novos caminhos da educação superior. In: 34 REUNIÃO ANUAL DA ANPED, 2011, Anais... Natal: Anped, 2011. Disponível em: <http://www.anped 11.uerj.br/GT11- 315\%20int.pdf>. Acesso em: 25 jul. 2013.

RAMOS, M. S. Limites e possibilidades do Pronatec como ação governamental de ampliação do acesso à educação profissional: uma análise a partir da experiência do IFRJ. Dissertação (Mestrado) - Programa de PósGraduação em Educação, Universidade Federal Rural do Rio de Janeiro, 2014, mimeo.

RIBEIRO, R. de S. Trabalho, educação e qualificação profissional: a pedagogia política dos programas do Governo Federal para a inclusão social de jovens. In: V ENCONTRO BRASILEIRO DE EDUCAÇÃO, MARXISMO, E EMANCIPAÇÃO HUMANA, 2011. Anais... Florianópolis: UFSC, 2011. Disponível em: <http://www.5ebem.ufsc.br/trabalhos/eixo_03/e03c_t002.pdf> . Acesso em: 20 ago. 2013.

RODRIGUES, J. O moderno príncipe industrial. Campinas: Autores Associados, 1998. 
SANTOS, J. S. Questão social: particularidades no Brasil. Rio de Janeiro: Cortez Editora, 2012.

SAVIANI, D. Pedagogia histórico-crítica. Campinas: Autores Associados, 2012a.

. Escola e democracia. Campinas: Autores Associados, 2012b.

SEMERARO, G. Gramsci e a sociedade civil: cultura e educação para a democracia. Petrópolis: Editora Vozes, 2001.

. Gramsci e os novos embates da filosofia da práxis. Aparecida, SP: Editora Ideias e Letras, 2006.

SOUZA, D. B. de S.; SANTANA, M. A. S.; DELUIZ, N. Trabalho e educação: centrais sindicais e reestruturação produtiva no Brasil. Rio de Janeiro: Quartet Editora, 1999.

SOUZA, J. dos S. Trabalho, educação e sindicalismo no Brasil - anos 90. Campinas: Autores Associados, 2002.

STAMPA, I. E agora, companheiros? Ação sindical dos ferroviários do Rio de Janeiro e a reinvenção da política. Tese (Doutorado) - Programa de Pós-Graduação em Serviço Social da PUC-Rio, Rio de Janeiro, 2007.

Recebido em 21 de julho de 2015.

Aprovado para publicação em 17 de dezembro de 2015.

DOI: $10.12957 /$ rep.2016.27862

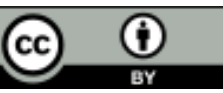

A Revista Em Pauta: Teoria Social e Realidade Contemporânea está licenciada com uma Licença Creative Commons Atribuição 4.0 Internacional. 